\title{
Hiperbólicos italianos: as viagens dos integrantes da Escola Positiva de Antropologia da Itália pela América meridional, 1907-1910
}

\author{
Hyperbolic Italians: the travels of the members of the Positive \\ School of Anthropology of Italy in South America, 1907-1910
}

\author{
Livio Sansone $e^{i}$ \\ ' Professor, Departamento de \\ Antropologia/Universidade Federal \\ da Bahia. \\ Salvador - BA - Brasil \\ orcid.org/0000-0003-3837-6049 \\ sansone@ufba.br
}

Recebido em 19 fev. 2019.

Aprovado 2 abr. 2019.
SANSONE, Livio. Hiperbólicos italianos: as viagens dos integrantes da Escola Positiva de Antropologia na Itália pela América meridional, 19071910. História, Ciências, Saúde - Manguinhos, Rio de Janeiro, v.27, n.1, jan.-mar. 2020, p.265-274.

Resumo

Com base em pesquisa realizada na Itália, no Brasil, na Argentina e nos EUA, proponho reconstruir, ainda de forma preliminar, o momento, o clima político e o debate suscitado na Argentina e no Brasil pela visita de Guglielmo Ferrero e sua esposa, Gina Lombroso Ferrero, em 1907, e as duas viagens do jurista e sociólogo da criminalidade Enrico Ferri em 1908 e 1910. Esses três intelectuais italianos associados à Escola Positiva de Criminologia de Turim, liderada pelo médico e antropólogo físico Cesare Lombroso, visitam o Brasil, a Argentina, o Uruguai e o Chile, a convite, entre outros, da Academia Brasileira de Letras e do periódico argentino $\mathrm{La}$ Nación.

Palavras-chave: Cesare Lombroso (1835-1909); atavismo; degeneração; miscigenação; Guglielmo Ferrero (1871-1942).

Abstract

This study, based on research undertaken in Italy, Brazil, Argentina, and the USA, presents a preliminary reconstruction of the time, the political climate, and the debate sparked in Brazil and Argentina by the visit of Guglielmo Ferrero and his wife, Gina Lombroso Ferrero, in 1907, and two voyages by the jurist and criminal sociologist Enrico Ferri in 1908 and 1910. These three Italian intellectuals associated with the Positive School of Criminology in Turin, led by the physician and physical anthropologist Cesare Lombroso, visited Brazil, Argentina, Uruguay, and Chile on the invitation, among others, of the Brazilian Academy of Letters (Academia Brasileira de Letras) and the Argentinean newspaper La Nación.

Keywords: Cesare Lombroso (1835-1909); atavism; degeneration; miscegenation; Guglielmo Ferrero (1871-1942).

http://dx.doi.org/10.1590/S0104-59702020000100015 
$\mathrm{E}$ ntre 1907 e 1910 três intelectuais italianos associados àquela que eu chamo de Galáxia Lombroso - a rede que existia ao redor da Escola Positiva de Criminologia de Turim liderada pelo médico e antropólogo físico Cesare Lombroso - visitam o Brasil, a Argentina, o Uruguai e o Chile, a convite, entre outros, da Academia Brasileira de Letras (ABL) e do periódico argentino La Nación. Embora essas viagens tenham recebido pouca atenção de parte de pesquisadores interessados na recepção dos positivistas italianos em nossa região, ${ }^{1}$ elas iluminam uma fase específica das relações intelectuais entre a América do Sul e a Itália - frequentemente com a participação de intelectuais espanhóis e portugueses, que atuavam como intermediários e/ou tradutores - em torno da construção das noções de raça, degenerescência, atavismo, novo e velho mundo, ascensão/decadência de um determinado povo e, com mais força ainda, raça latina, ${ }^{2}$ que eram centrais no debate da época. Com base em pesquisa realizada na Itália, no Brasil, na Argentina e nos EUA, ${ }^{3}$ tenciono reconstruir, ainda de forma preliminar, o momento, o clima político e o debate suscitado pela visita de Guglielmo Ferrero e sua esposa, Gina Lombroso, filha do próprio Cesare, e as duas viagens do jurista e sociólogo da criminalidade Enrico Ferri. ${ }^{4}$ Essas viagens foram, ademais, uma autêntica embaixada na região da parte do já velho Lombroso, que as estimulou ativamente e as acompanhou por cartas. As viagens contribuíram para aumentar bastante a popularidade e a reputação do "mestre" Lombroso no Cone Sul, justamente quando sua "cientificidade" começava a ser criticada em seus fundamentos na Europa. Isso se deu, sobretudo, a partir da escola de Lacassagne baseada em Lion no segundo Congresso de Antropologia Criminal realizado em Paris em 1889 e, uma década depois, por, entre outros, Gustave Le Bon na França - que salientava o descarrilhar do velho Lombroso do caminho positivista com sua tardia paixão pela "etnografia dos espíritos" e o espiritismo em geral - e, na Itália, sobretudo por parte de pensadores católicos, socialistas ou progressistas - dentre os quais se destacava Napoleone Colajanni.

Guglielmo Ferrero era formado em direito, foi ensaísta, jornalista e, ainda jovem, foi autor junto com Cesare Lombroso do livro La donna delinquente, publicado em Turim em 1893. Essa obra teve grande impacto sobretudo nos mundos de língua inglesa (tendo sido traduzida para o espanhol e o português somente nos anos 1930). ${ }^{5}$ Mais tarde, já na sua nova função de historiador e divulgador, escreveu Grandeza e decadenza di Roma (Milão: Treves, 1904-1907), obra em seis volumes publicada durante quatro anos (1904-1907) e que chegou a ser muito popular entre intelectuais de toda a América Latina. ${ }^{6}$ Foi nomeado membro correspondente da ABL em 1906 (o último italiano a receber essa honra, na cadeira que é hoje do historiador Lesley Bethell). Por volta de maio de 1907, Bartolemé Mitre, proprietário do diário La Nación de Buenos Aires, após ter escutado suas conferências no Collège de France, convidou Ferrero a visitar a Argentina, ocasião em que este realizou um ciclo de 12 conferências no teatro Colón. Rapidamente a notícia desse convite chegou aos ouvidos do barão do Rio Branco, titular do Itamaraty, que, por meio de Graça Aranha, naqueles anos vinculado ao mesmo ministério, comunicou à $\mathrm{ABL}$ que seria interessante aproveitar a visita de Ferrero à Argentina para convidá-lo a ministrar algumas palestras e "conhecer o Brasil" durante dois meses - outubro e novembro de 1907 - depois da passagem pela Argentina e pelo Uruguai. Os recursos, informou o barão do Rio Branco em sua correspondência com Machado de Assis, seriam disponibilizados pelo Ministério da Viação. 
Ferrero prontamente aceitou e viajou em companhia da esposa, Gina Lombroso, médica, socióloga e ativista socialista - uma intelectual já conhecida por suas pesquisas sobre a mulher e por sua provocativa tese em medicina, publicada em livro, sobre as vantagens da degeneração (um fenômeno que produziria loucos, mas também gênios). Em sua viagem de ida para Buenos Aires, iniciada no porto de Gênova, o casal, que trouxe consigo o pequeno filho Leo e uma babá, chegou na tarde do dia 27 de junho na baía de Guanabara, onde era esperado por uma lancha com uma delegação de peso da ABL que os levou por uma volta noturna de carro - de fato quase uma corrida - pela cidade e que culminou com um jantar de gala no palácio do Itamaraty. Guglielmo e Gina ficaram positivamente impressionados e se sentiram lisonjeados. Voltaram a embarcar por volta da meia-noite. De madrugada, o navio zarpou rumo a Buenos Aires.

Em suas cartas a Machado de Assis e nas anotações sobre essa viagem publicadas no seu livro Le genie latin et le monde moderne (Ferrero, 1917, p.127-142), do qual saíram versões em várias línguas, Ferrero se oferece para ministrar oito conferências (acabaram por ser seis), duas por semana. Durante sua permanência ele pede para ficar somente um mês no Rio, para que no outro pudesse conhecer outras cidades do país. Ferrero pede cinco mil francos, e Machado de Assis, em uma série de cartas que se encontra no arquivo da $\mathrm{ABL}$, aceita de bom grado, sem questionar o valor pedido. Ferrero responde às gentilíssimas missivas de Machado, nas quais é detalhado que o valor a ser pago será isento de impostos e que, ademais, Ferrero e sua esposa terão hospedagem e deslocamentos pagos. Ferrero replica com a mesma gentileza e usa uma arma infalível na negociação com os representantes da ABL: em cartas de 12 e 26 de agosto de 1907, escritas em Mendoza e Buenos Aires, além de apontar que o Rio de Janeiro - e não Buenos Aires - seria a capital cultural da América meridional, sugere que no Rio sejam ministradas não as conferências que proferiu em Buenos Aires para um grande público e "de nível médio", mas aquelas já ministradas em Paris no início do ano, sugerindo que o público do Rio seria tão culto e selecionado como aquele do Collège de France em Paris - e menos burguês de classe média como efetivamente foi o público em Buenos Aires.

Evidências de uma vida associativa mais densa, sobretudo em torno das associações operárias e socialistas em Buenos Aires e São Paulo mais do que no Rio de Janeiro, e de um público efetivamente diferente, mais numeroso e de classe média em Buenos Aires e mais aristocrático no Rio, com São Paulo em uma posição intermediária, podem ser achadas nas fotos das conferências e dos inúmeros banquetes e recepções publicadas no semanário argentino Caras y Caretas, no diário do mesmo país La Nación e nas primeiras páginas dos principais jornais cariocas e paulistas da época. ${ }^{7}$ Em Buenos Aires e São Paulo foram muitos os encontros com patronatos, sindicatos e associações operárias e socialistas, além das câmaras de comércio, das associações dos donos de indústrias e fábricas e das associações italianas. Também as cartas e bilhetes dos admiradores - que no caso de Gina e Ferrero se acham numerosos nos arquivos da Columbia University e Viesseaux de Florença, e que também se acham no caso de Ferri, embora mais raros, porque a correspondência de Ferri está geralmente em péssimo estado - revelam que em Buenos Aires e, em menor medida, São Paulo havia um público de classe média ilustrado, inclusive dentro da grande comunidade italiana, mas também tinha um público mais popular, composto por sindicalistas, lideranças 
italianas e anônimos trabalhadores atraído pela aura socialista (Ferri e Gina) ou radical (Ferrero) dos convidados italianos. Esses trabalhadores eram quase sempre de origem italiana e frequentemente pediam a intercessão dos convidados em casos na justiça argentina ou brasileira ou um apoio na busca de emprego. As cartas e os bilhetes oriundos do Rio de Janeiro que pude analisar eram quase todos de integrantes da ABL.

O casal regressa ao Rio de Janeiro vindo de Buenos Aires no vapor Umbria no dia 23 setembro. Nas primeiras páginas do Jornal do Brasil há uma descrição minuciosa da acolhida. Mais uma vez em uma lancha fretada, deu-lhes as boas-vindas uma importante delegação da ABL composta por Machado de Assis, Graça Aranha, Souza Bandeira e Mario Alencar. Na lancha encontra-se também o comitê da loja maçônica Grande Oriente do Brasil. ${ }^{8}$ Ainda a bordo o casal recebeu a imprensa e logo se deixou tentar pela comparação entre Buenos Aires e Rio - ao que parece, essa era a principal indagação dos periodistas. Buenos Aires seria planejada e quase monótona, mas muito bem organizada; o Rio seria uma cidade mais bonita e irregular em seu desenho, por estar imersa na natureza. Elogiam os serviços públicos da Argentina, mas detestam a obsessão em copiar tudo aquilo que é - ou seria de origem europeia.

Foram estes os temas das conferências oficiais ministradas no Rio, cujos textos foram publicados diariamente no Jornal do Commercio: "A cultura latina na atualidade"; "A corrupção romana"; "A vida cotidiana"; "Giulio e Tiberio"; "Nerone"; "Antonio e Cleopatra"; "A missão histórica do Império romano". No relatório de atividades redigido mais adiante por Afrânio Peixoto para uso interno da $\mathrm{ABL}$, as conferências seriam cinco, com temas levemente diferentes. Três dessas conferências em francês e as demais em italiano ("língua bela e canora", nas palavras de Machado) foram no palácio Monroe, para o qual a ABL alugou cinquenta dúzias de cadeiras por 1.500 .000 réis. A primeira conferência foi realizada na mesma ABL no dia 26 de setembro, em italiano. O texto foi logo traduzido, para o francês, em uma brochura da Academie Française, que o retomou da versão em português publicada integralmente no diário Jornal do Commercio.

Além das conferências proferidas por Ferrero, o casal teve muitos encontros com intelectuais e representantes da comunidade italiana, juristas e médicos. No Jornal do Commercio do dia 18 de novembro de 1907 se chega a anunciar que "A ordem do dia nos círculos intelectuais do Rio é Guglielmo Ferrero". Durante sua estada, o casal foi ciceroneado, sobretudo, por José Veríssimo, Graça Aranha e Machado de Assis, que o levaram várias vezes aos lugares importantes da intelligentsia da época: a livraria Garnier, o templo espírita - o casal era espírita - Templo da Humanidade, na rua Benjamin Constant, onde tem lugar uma longa conversa com o sacerdote-mor Teixeira Mendes (Ferrero, 1913, p.170), e o horto botânico. O casal hospedou-se no Hotel Alexandra até o dia 12 de outubro. O hotel ficava ao pé do Corcovado, e "nele há um grande jardim que chega até a floresta virgem" (Lombroso, 1908, p.73). ${ }^{9}$ Desde o começo, Gina mostrou familiaridade com Machado, de quem lera dois livros, e estabeleceu amizade com a senhora Aranha, que a acompanhará pelo Rio. Ela e o marido passam um dia com o casal Aranha na praia de Icaraí (Ferrero, 1913, p.VI).

Mais adiante, no domingo 9 de outubro, eles chegaram a São Paulo acompanhados pelo governador do estado e por Graça Aranha, em um vagão especial de trem custeado pelo governo do estado, onde foram recebidos, informa o diário pessoal da Gina, por 
uma multidão de vinte a trinta mil pessoas no parque do Ipiranga que os aclamava com "Itália, Garibaldi, Lombroso" (Lombroso, 1908, p.4-62). Nessa cidade eles visitaram o novo complexo do Carandiru, que, junto com o manicômio open doors de Buenos Aires, continuaria a ser motivo de atenção e de vários artigos elogiosos na revista Archivio di Psichiatria, Scienze Penali e Antropologia Criminal, da qual Gina era a editora - revista que serviu de modelo para várias outras quase homônimas na Argentina, no México, em Cuba e, mais adiante, no Brasil (já com Leonidio Ribeiro). Se em Buenos Aires Gina chegou a se encontrar com o incipiente movimento sufragista, na ausência, naqueles anos, de grupos equivalentes no Brasil, ela manteve vários encontros com grupos de mulheres.

Foram dois meses muito intensos, e Ferrero declara ao jornal O Estado de S.Paulo de 21 de outubro de 1907 que no Brasil ele ministrou 28 conferências, tendo participado de 24 banquetes e 25 homenagens. Efetivamente, se pesquisarmos jornais e revistas da época, tanto paulistanos (O Estado de S.Paulo, Correio Paulistano, Diário Popular e Comércio de S.Paulo) como cariocas (Jornal do Brasil, O Malho), corroboram-se as informações do diário de viagem de Gina: as conferências foram um grande sucesso, e o casal foi frequentemente aclamado por autênticas multidões, nas quais havia obviamente uma forte presença de imigrantes italianos. Isso deveu-se não somente à grande popularidade de Ferrero, sua simpatia e ars oratoria (que impressionou a imprensa), mas à relevância, no momento, da questão da degeneração (do Velho Mundo) e da ascensão (do Novo Mundo). Falar da ascensão e decadência da antiga Roma era como falar do Velho Mundo, da Velha Europa daquela época, onde o sangue e o gênio latino (eram esses os termos) não mais tinham como florescer. Sugeriam os italianos que o gênio latino pudesse crescer e contribuir para o sucesso das jovens nações das Américas, sobretudo da América do Sul - que em si ainda não conheciam a degeneração e, por isso, ainda não tinham produzido nem muita loucura nem muitos gênios.

Ferrero (21 abr. 1908, p.12) replica os elogios recebidos com um longo artigo no prestigioso cotidiano parisiense Le Figaro, onde ele não somente agradece o tratamento recebido, mas louva a iniciativa de haver sido criada no Brasil uma ABL porque

aqueles que nós definimos como povos jovens das Américas, de ter terras, minas, florestas e imigrantes ... também necessitam de uma cultura intelectual, porque sem essa hoje não é mais possível para um Estado ou uma Nação, na Europa e na América, se organizar e viver ... A alta cultura não é um luxo, mas uma força necessária. A ABL demonstra que o Brasil é o país da América meridional que mais esforços tem envidado para resolver o problema da cultura nacional.

Com efeito, o sucesso da visita se devia também ao apoio da ABL e do governo, sobretudo do Itamaraty. A vinda do casal, e o sucesso de público, se inseria no projeto do barão do Rio Branco para que intelectuais estrangeiros de destaque (logo depois foi convidado o francês Clemenceau) escrevessem (bem) sobre o Brasil. Efetivamente, o casal Ferrero-Lombroso recebeu todas as honras de Estado - e até um vagão especial foi colocado nos trens para que conhecesse parte do Brasil, com o próprio Rio Branco o acompanhando na viagem para São Paulo, e indicando seu assistente Graça Aranha para que o seguisse de perto durante o resto da viagem. 
PALAVRAS DO SR. MACHADO DE ASSIS A0 SR. GUGLIELMO FERRERO

S. Gugfielma Fetreto,

I Academia Brazileiza canaidau-oos a dar algumas canferencias nesle paiz. Cantaona de cetla cam a admizagãa que the haviam imposta as oossas escritas, mas a oossa palaoza excedeu a sua confiansa. Oäa é zaza que as duas fármas de pensamento se conjuguem na mesma pessoa; conheciamos aqui esle fenomena e sabiamos delle em oukas partes, mas foi precisa ousir-oos paza senlil-a ainda uma oez berm, e por outra lingua canaza e magnifica.

Hgata que ides deixar-nas lemazeis á Flalia, e pat ella aa resta da munda curopeu, a nalicia da nossa grande entusiasma. Cieio que leaareis mais. $\mathcal{O}$ que o Brazil zeaclau da sua crescente prasperidade a eminente Ristoriador de Rama ler-lhe-ha maskada que este pedaga da America näa desmente a nobieza da estirpe lalina e ciè na papel que de futura the cabe. E se com essa impressäa palitica leaardes tamberm a da simpalia pessaal e profunda que inspizastes a lodas nós, a Academia Brazileira folgazá duas aezes pela impula da seu acta de canaile, e aqui vala declaza, aferecenda-aas esle banquete.

Ria de Fanciza, 31 de Oulubiza de 1907.

Figura 1: Palavras de Machado de Assis a Guglielmo Ferrero (Arquivo da ABL, Fundo Machado de Assis)

No diário de viagem de Gina por Brasil, Uruguai e Argentina, publicado em 1908 em formato de livro - de fato, um detalhado relato com observações em parte aproximativas e em parte etnográficas -, há muitas referências positivas à contribuição dos negros à cultura e aos hábitos dos brasileiros assim como à mestiçagem em terras brasileiras. Os mestiços no Brasil seriam lindos e, por vezes, mais capazes do que os brancos. Os negros trouxeram doçura e cordialidade para a cultura brasileira. O Brasil conseguiria se reerguer depois da escravidão sem chegar aos extremos dos EUA. O diário está repleto de observações sobre o mundo do trabalho e, mais detalhadamente, as fazendas de café, do vale do Paraíba, com os braceiros italianos tomando o lugar dos negros e as relações cordiais entre donos e trabalhadores brancos e negros. Evidente que a perspectiva de Gina reflete em boa parte as conversas e a estada nas próprias fazendas, onde eles eram sempre hóspedes dos donos. Tratava-se, ademais, de fazendas escolhidas pelos organizadores do tour. Não obstante tudo, as observações de Gina são interessantes e são mais uma prova de que havia ideias freyrianas presentes em certas elites já bem antes da popularização da obra de Gilberto Freyre. 
Enrico Ferri, advogado criminalista e autor do clássico Sociologia criminal, veio para os mesmos países, mais o Chile, duas vezes, em 1908 e 1910, ao que parece em tours de conferências muito bem pagas, organizados pelo mesmo empresário que tinha trazido para o Brasil Eleonora Duse e Caruso. Ministrou em Buenos Aires e no Rio de Janeiro o ciclo completo de dez conferências, dando mais algumas em São Paulo, Rosário, Santiago e Montevidéu. Os temas das conferências foram bastante variados e, digamos assim, singulares: o amor e o pão, como educar os filhos, as maravilhas do século XX, a conquista da felicidade, o café, socialismo e ciência, Jesus, o homem delinquente, sociologia criminal, a mulher, os grandes navegadores, a república Argentina, a solidariedade e o pan-americanismo. Todas as conferências se realizaram em grandes e prestigiosos espaços (como o palácio Monroe no Rio de Janeiro) e foram um sucesso de público - sobretudo a primeira viagem recebeu a atenção com destaque na primeira página dos principais jornais do Rio, São Paulo e Buenos Aires. Correio Paulistano e La Nación publicaram quase de forma integral, como já tinham feito com Ferrero, o texto das conferências.

Entre juristas e os alunos da Faculdade de Direito de São Paulo, que já tinham recebido muito bem Ferrero e Gina Lombroso (Ferrero chegou a fazer uma grande conferência naquela Faculdade), as duas viagens de Enrico Ferri suscitaram entusiasmo. Em 1908, Ferri ministrou uma grande e solene palestra nessa faculdade e foi ovacionado. A revista da Faculdade dedica um longo artigo à visita. Diversamente do Rio de Janeiro, em São Paulo Ferri ganhou também a profunda aversão da Igreja católica. Padre João Gualberto de Amaral, conhecido docente de teologia moral e direito canônico no Seminário de São Paulo, nele via um alferes de uma sociologia iconoclasta que não se preocupava sequer em traçar, em uma de suas 12 conferências públicas, uma biografia de cristo, como exemplo de gênio e desvio (Amaral, 1948). Vale a pena lembrar que a Igreja católica tinha uma relação de duro confronto com a Galáxia Lombroso. Padre Gemelli chegou a celebrar como bem-vinda a morte de Lombroso em 1909, anunciando não somente o funeral de um homem, mas de uma doutrina, pois com ele morreria também uma disciplina (Gemelli, 1910). Ferri, parlamentar socialista, manteve uma relação tensa com os socialistas da terra e com aqueles de origem italiana, sobretudo em Buenos Aires, por declarar que Argentina e Brasil ainda não estavam prontos para experimentos socialistas - as forças produtivas ainda não seriam suficientemente desenvolvidas. Ferri entra em polêmica com pelo menos dois expoentes dos pensamentos socialista e anarquista: o famoso anarquista italiano Oreste Ristori, que mais adiante migraria para o Brasil e do qual será expulso para a Itália fascista, onde será fuzilado em 1944, e o sociólogo bonaerense Ernesto Quesada, que naqueles anos era, junto com José Ingenieros, a personalidade de destaque da incipiente sociologia argentina. Em Buenos Aires, num ambiente intelectual mais denso e com universidades estruturadas como em La Plata, onde ele ministrou parte das conferências em 1910, Ferri também se deparou com a oposição de grupos de suffragettes que o acusaram de pregar a inferioridade psicológica da mulher. É interessante que esses grupos, assim como várias associações de mulheres, tenham recebido de forma diferente Gina Lombroso três anos antes. Tenho a impressão de que isso se devia muito à forma pela qual as ideias eram apresentadas, com Gina enfatizando a importância da mulher na sociedade, mas com uma fala relativamente meiga e conciliadora, e Ferri, ao contrário, com uma ars oratoria quase de estilo operístico e o constante sublinhar da importância da virilidade. ${ }^{10}$ 
Se as reações da imprensa, sobretudo na Argentina, mostram que esses autores podiam e deviam ser também criticados, não havendo nenhum tipo de recepção passiva, sobretudo quando tocavam em questões do lado de cá (como o socialismo na Argentina por parte de Ferri ou o cesarismo latino por parte de Ferrero, ou as considerações sobre a centralidade dos negros no Brasil por parte de Gina Lombroso), o grande sucesso de público dessas viagens e conferências pode ser explicado pela feliz combinação de fatores e de várias agendas. Os temas tratados atraíam por estar afinados com alguns grandes debates intelectuais na região, assim como com as preocupações de uma crescente classe média culta (savant, como a definiu Ferrero). Em segundo lugar, certamente pairava a aura de Cesare Lombroso nessas conferências, um autor que por aqui era tanto citado e reverenciado quanto efetivamente pouco lido, pelo menos em primeira mão. ${ }^{11}$ Houve também uma combinação de agendas: do ministro barão do Rio Branco, da ABL, da Faculdade de Direito de São Paulo, dos empresários organizadores, da liderança da comunidade italiana, e dos próprios intelectuais convidados. Rio Branco - de alguma forma por meio da $\mathrm{ABL}$ - tinha um projeto de autêntica impression management na promoção da imagem do Brasil no exterior; ${ }^{12}$ os juristas e a Faculdade de Direito celebraram a vinda de mestres, ademais discípulos do grande mestre Lombroso e nisso davam também um sinal à Faculdade de Direito de Recife que, até então, tinha sido a principal intérprete das ideias lombrosianas no Brasil; os empresários teatrais que organizaram os tours ganharam dinheiro e notoriedade; e os conferencistas ganharam reconhecimento internacional (e um bom cachê).

A vinda do casal e de Ferri foi de particular importância porque seguia a imigração em massa de italianos para Brasil, Uruguai e Argentina. Por um lado, era um momento de efervescência na vida associativa das comunidades italianas na América do Sul. Por outro, era época de colonialismo, e na Itália, nação jovem onde as elites também estavam preocupadas com o lugar do país na Europa e não às margens dela, o debate vertia também sobre a conveniência de possuir colônias. Havia quem as quisesse pelas armas na África, outros, entre eles muitos socialistas, que as preferiam "pelos braços dos trabalhadores" na América do Sul. Os jornais italianos da época, inclusive o socialista Avanti, do qual Ferri foi o diretor de 1903 a 1907, orgulhavam-se do sucesso desses intelectuais italianos nas Américas: gênio itálico e latino, pouco valorizado na jovem, mas já decadente, Itália, e que finalmente ganhava seu reconhecimento do outro lado do oceano. Era a prova de que a Itália podia ser grande, mesmo sem ter colônias, como França e Inglaterra, e que além de milhões de braços podia exportar muitos cérebros.

A análise dessas viagens ajuda a compreender uma fase muito particular dos intercâmbios transatlânticos entre América do Sul e Europa, sobretudo a Itália e, em certa medida, a Europa "latina", na qual a primeira podia se permitir convidar - e pagar bem - intelectuais estrangeiros de renome para ministrar grandes conferências em lugares privilegiados, tais como o palacete Monroe, no Rio de Janeiro, ou o teatro Colón em Buenos Aires. Era o período que precedia a formação das ciências sociais e das universidades - no Brasil ou sua consolidação - na Argentina. Era também o período em que ainda se falava das Américas, uma América do Norte majoritariamente protestante e uma América do Sul ou Meridional mais católica e mais simpática às ideias dos italianos e dos "latinos" em geral. Como sabemos, nas décadas seguintes e, com mais força, a partir dos anos 1930, a região 
começou a ser chamada, com crescente frequência, de América Latina - termo que, do ponto de vista da pesquisa, se afirmará junto com o aumento da subalternidade de nossa região em relação ao Norte e, mais especificamente, aos cientistas sociais da Europa e dos EUA, dentro de um processo de consolidação e compartimentalização das ciências sociais e das ciências médicas.

\section{AGRADECIMENTOS}

O projeto se beneficiou de uma bolsa de estágio doutoral sênior da Capes por meio da qual realizei pesquisa na Itália em 2014.

\section{NOTAS}

${ }^{1}$ Uma parcial exceção são Caimari (2009) no caso da Argentina, Ruiz Diaz (2016) no caso da visita de Gina Lombroso e Ferrero à Penitenciaria Nacional de Buenos Aires, e Varejão (2005) para o Brasil. Na ocasião do centenário da morte de Lombroso, em 2009, ocorreu um grande crescimento do interesse pelo conjunto de sua obra, assim como pela reinterpretação de seus trabalhos em vários países. Na análise desse fato com relação ao mundo anglófono e ao impacto do livro, destaca-se Mary Gibson (2002).

${ }^{2}$ Uma expressão cuja relativamente rápida popularidade entre os intelectuais brasileiros se deve à influência da alvorada do modernismo latino-americano, despoletado, entre outros, por Juan Rodo, Ruben Darío e, no Brasil, José Veríssimo entre 1900 e 1907 (Preuss, 2013; Villafañe G. Santos, 2018).

${ }^{3}$ Arquivo do Museu Lombroso da Universidade de Turim, Arquivo Viesseaux de Florença, Coleção Ferrero na Rare Manuscript Section do Arquivo da Columbia University em Nova York, Arquivo do Socialismo Italiano Turati de Florença, Fondo Ingenieros no Centro de Documentación e Investigación de la Cultura de Izquierdas en la Argentina (CeDInCI) na Universidade S. Martin, Arquivo da Academia Brasileira de Letras e Fundação Casa Rui Barbosa no Rio de Janeiro.

${ }^{4}$ Esta pesquisa é parte de um projeto maior, apoiado com bolsa de estágio pós-doutoral sênior da Capes e do CNPq, que trata da rede de contatos e intercâmbio de objetos e ideias entre o Gabinete Lombroso e a América Latina, cujo título é "'A galáxia Lombroso', a África e a América Latina”.

${ }^{5} \mathrm{Na}$ introdução da nova e recente tradução desse livro para o inglês, Mary Gibson e Nicole Rafter (2004) salientam como esse livro sobre o universo feminino tornou a obra de Lombroso conhecida nos países de fala inglesa. O homem delinquente foi traduzido (e mal) para o inglês somente vários anos depois. Vale a pena salientar que na América Latina, pelo contrário, foi O homem delinquente o primeiro vetor da obra lombrosiana, enquanto $A$ mulher delinquente foi acessível em língua vernácula muitas décadas depois. A primeira tradução completa da qual estou ciente em língua portuguesa é de 2017 (Lombroso, Ferrero, 2017).

${ }^{6}$ Foi publicada em português pela editora Globo em 1963.

${ }^{7}$ Pesquisei, sobretudo, o Diário Paulistano, o Diário Popular, O Estado de S.Paulo, a Deutsche Zeitung für S. Paulo e o Jornal do Commercio.

${ }^{8}$ Nos arquivos da Columbia University encontra-se a maior parte da documentação referente a Guglielmo Ferrero, que, antifascista, morreu exilado em Genebra, em 1942. No Instituto Viesseaux em Florença, há um importante fundo dedicado a Gina Lombroso Ferrero. Nele se acham vários convites da loja maçônica Grande Oriente destinados a Ferrero. No arquivo em Florença encontra-se também um diário da viagem pela América meridional, que representa o núcleo do livro homônimo escrito por Gina, e dois manuscritos, um em italiano e outro em francês, com esboços de uma autobiografia.

${ }^{9}$ Como era recorrente nos diários de viagem pelos trópicos, um gênero de literatura de viagem em franco crescimento na Europa naquela época, até mesmo na Itália, o tema da natureza luxuriante em oposição à natureza supostamente mais "avarenta" da Itália está bem presente no diário de Gina. A publicação desse diário em formato de livro, em 1908, foi bastante criticada em vários jornais, como em O Paiz de 27 de novembro de 1908, e mereceu a charge "Escritoras estrangeiras" no implacável O Malho (n.411, p.40, 1911), por ser considerado superficial e salientar uma série de aspectos do Brasil, como as doenças e a presença importante dos negros, que não deveriam ter sido apresentados ao público europeu. Na minha opinião, esse livro, além de ser certamente aproximativo em vários pontos, evidencia quanto uma série de noções sobre a mestiçagem e a centralidade do negro na cultura popular, geralmente associadas a Gilberto Freyre, 
estavam presentes, de forma embrionária, na obra de José Veríssimo e outros integrantes da ABL que Gina cita copiosamente.

${ }^{10}$ Não quero com isso dizer que as ideias realmente inovadoras contidas no primeiro importante livro de Gina publicado em 1904 sobre as vantagens da degeneração (Lombroso, 1904), e traduzido muito mais tarde para o espanhol, não possam ter contribuído para sua maior aceitação por parte das sufragistas argentinas.

${ }^{11} \mathrm{O}$ fato de ser citado até por aqueles que não se preocupam em ler o texto original, nem quando esse aparece traduzido em português ou espanhol, é uma das caraterísticas da recepção e reinterpretação de Lombroso na América Latina que tenciono aprofundar em minha pesquisa, na qual detalho como a imprecisão teórica, o ecletismo, a amplitude dos interesses e o poligrafismo de Lombroso contribuem para manter sua popularidade nas áreas de conhecimento às margens das ciências sociais (ciências policiais, antropologia criminal ou forense, psiquiatria, endocrinologia etc.) em nossa região, mesmo quando sua influência sobre o cânone das ciências sociais diminui.

12 Projeto que seus detratores, como Sílvio Romero, chamavam de "Embaixada de Ouro", porque o compreendiam como uma forma de "entreguismo" dos interesses brasileiros, mais do que como uma campanha de opinião internacional.

\section{REFERÊNCIAS}

AMARAL, João Gualberto do.

A refutação a Ferri: três conferências realizadas em São Paulo em 1908. Petrópolis: Vozes. 1948.

CAIMARI, Lila.

L'America Latina. In: Montaldo, Silvano; Tappero, Paolo (Ed.). Cesare Lombroso cento anni dopo. p.193-201. Milano: Utet. 2009.

FERRERO, Guglielmo.

Le genie latin et le monde moderne. Paris:

Gallimard. 1917.

FERRERO, Guglielmo.

Entre les deux mondes. Paris: Plon. 1913.

FERRERO, Guglielmo.

Une Academie Americaine. Le Figaro, p.12. 21 abr. 1908.

GEMELLI, Agostino.

I funerali di un uomo e di una dottrina. Monza: Tipografia Artigianelli. 1910.

GIBSON, Mary.

Born to crime: Cesare Lombroso and the origins of biological anthropology. Westport, CT:

Greenwood Press. 2002.

GIBSON, Mary; RAFTER, Nicole. Editors' introduction. In: Lombroso, Cesare; Ferrero, Guglielmo. Criminal woman, the prostitute and the normal woman. Durham: Duke University Press. p.5-17. 2004.
LOMBROSO, Cesare; FERRERO, Guglielmo. A mulher delinquente, a prostituta e a mulher normal. Trad. Antonio Fontoura. Curitiba: Antonio Fontoura. E-book. 2017.

LOMBROSO, Gina.

Nell’America Meridionale. Torino: Treves. 1908.

LOMBROSO, Gina.

I vantaggi della degenerazione. Torino: Bocca. 1904.

PREUSS, Ori.

Discovering "os ianques do sul": towards an entangled Luso-Hispanic history of Latin America. Revista Brasileira de Política Internacional, v.56, n.2, p.157-176. 2013.

RUIZ DIAZ, Matias.

Europa y America: Guglielmo Ferrero y Gina Lombroso en la Penitenciaría Nacional de Buenos Aires (1907). Anales del IAA, v.46, n.1, p.77-90. 2016.

VAREJÃO, Marcela

Il positivismo dall'Italia al Brasile (1822-1935). Milano: Giuffré. 2005.

VILLAFAÑE G. SANTOS, Luis Claudio. Yo panamericanicé: Ruben Darío en Brasil. Managua: Hispamer. 2018. 